What is eSports and why do people watch it?

\title{
What is eSports and why do people watch it?
}

\author{
Juho Hamari
}

Game Research Lab, School of Information Sciences, University of Tampere

Max Sjöblom

Game Research Lab, School of Information Sciences, University of Tampere

\begin{abstract}
Purpose: In this study we investigate why do people spectate eSports on the internet. We define eSports (electronic sports) as a form of sports where the primary aspects of the sport are facilitated by electronic systems; the input of players and teams as well as the output of the eSports system are mediated by humancomputer interfaces. In more practical terms, eSports refer to competitive video gaming (broadcasted on the internet).
\end{abstract}

Methodology: We employed the MSSC (Motivations Scale for Sports Consumption) which is one of the most widely applied measurement instruments for sports consumption in general. The questionnaire was designed and pre-tested before distributing to target respondents $(\mathrm{N}=888)$. The reliability and validity of the instrument both met the commonly accepted guidelines. The model was assessed first by examining its measurement model and then the structural model.

Findings: The results indicate that escapism, acquiring knowledge about the games being played, novelty and eSports athlete aggressiveness were found to positively predict eSport spectating frequency.

Originality: During recent years, eSports (electronic sports) and video game streaming have become rapidly growing forms of new media in the internet driven by the growing provenance of (online) games and online broadcasting technologies. Today, hundreds of millions of people spectate eSports. The present investigation presents a large study on gratification-related determinants of why people spectate eSports on the internet. Moreover, the study proposes a definition for eSports and further discusses how eSports can be seen as a form of sports.

Keywords: media consumption; online video; uses and gratifications; streaming; eSports; games 
What is eSports and why do people watch it?

\section{Introduction}

eSports is as a form of sports where the primary aspects of the sport are facilitated by electronic systems; the input of players and teams as well as the output of the eSports system are mediated by human-computer interfaces. In more practical terms, eSports commonly refer to competitive (pro and amateur) video gaming that is often coordinated by different leagues, ladders and tournaments, and where players customarily belong to teams or other 'sporting' organizations who are sponsored by various business organizations. During recent years, eSports (electronic sports) have become one of the most rapidly growing forms of new media driven by the growing provenance of (online) games and online broadcasting technologies. It has been estimated that more than 70 million people watched eSports during 2013 (Warr, 2014).

Like other media, media content consumption and information technology adoption research, the research on sports consumption and spectatorship is commonly interested in the motivations of why people consume it, how they consume it, as well as what kinds of needs the given form of media/technology might gratify. Thus far, sports consumption research has been mostly conducted in the area of sports management. However, with the rise of eSports, sports are increasingly becoming a computer-mediated form of media and information technology which may entail novel ways of information technology use. This is especially so because eSports media content is conveyed through computerized broadcasting (such as internet streaming), and because the sporting activity itself is computer-mediated. This makes eSports an increasingly interesting subject of study for the area of information technology in general.

In this paper we seek to progress both the conceptual understanding of eSports by discussing what eSports is, as well as the understanding of the motivations of eSports consumers by empirically investigating which sports consumption motivations predict how much time people are likely to 
What is eSports and why do people watch it?

spend on watching eSports. We employ data from on an online survey that was conducted amongst people who have watched eSports online $(\mathrm{n}=888)$.

\section{Background}

\subsection{Defining eSports}

eSports have only recently enjoyed wide international adoption, and there is still resistance as to whether eSports can truly be considered as a sport. This conceptual conundrum is a pertinent issue for not only defining eSports, but also for drawing the boundaries of what we understand as being sports in general. It appears that many (especially the fans of 'traditional' sports) are of the opinion that eSports can't be called a sport, simply because the player competence is not measured via either their physical prowess or finesse as the eSports athletes appear to be simply sitting riveted to their chairs. In reality, the body and physical activities of the player are still an important part of the overall sporting activity (e.g. Witkowski, 2012). Although the outcome-defining events of the sport occur within the confines of an electronic, computer-mediated environment, it does not in any way imply that eSports cannot be physically taxing for the players (see also Taylor and Witkowski, 2010; Witkowski, 2009; Witkowski, 2012). How taxing eSports is physically depends on the modus of human-computer interaction that is required to control the game states of the game's software or system. In dancing (video)games for example, players are physically drained from interacting with the computer. eSports are commonly organized around specific genres of games, such as Multiplayer Online Battle Arenas (e.g. League of Legends, Dota 2), First-Person Shooters (e.g. Counter-Strike: Global Offensive), Real Time Strategy (e.g. Starcraft 2), Collectible Card Games (e.g. Hearthstone) or Sports games (e.g. FIFA-series), therefore they form many sub-cultures within eSports, in the same way that 'traditional' sports do. However, eSports are not commonly perceived as 'electronic' versions of 'traditional' sports such as soccer, basketball, or track and field sports even though such simulations of 'traditional' sports are also played as eSports (such as the FIFA and NHL games). 
What is eSports and why do people watch it?

While some conceptual and qualitative literature on eSports has emerged, only a few definitions have been proposed regarding eSports. Perhaps the oldest and most explicit definition by Wagner (2006) leans heavily on a definition of traditional sports originally provided by Tiedemann (2004), as: "an area of sport activities in which people develop and train mental or physical abilities ...”. In defining eSports, Wagner (2006) extends this general definition of sports with the addition of "in the use of information and communication technologies". However, we believe that this definition might leave too much room for interpretation and does not therefore solve the looming question of what sporting activities can be defined to be either an electronic sport or 'traditional' sport. This is mainly because when considering any current sport, many aspects of it are computer-assisted or computer-mediated (see e.g. Witkowski, 2012). The definition by Wagner (2006) also poses another problem since it refers to such a large set of activities that even office-based software training could be included as a sport. We also subscribe to the criticism presented by Witkowski (2012) that the definition might define electronic systems too narrowly in covering only "information and communication technologies", and that the definition might divert attention from the complex mixture of both physical and electronic aspects in eSports.

We believe that in a quest to define eSports we should focus more deeply on what constitutes the “e” in eSports (for more cultural descriptions of eSports please see: Taylor, 2012; Taylor \& Witkowski, 2010; Witkowski, 2009; Witkowski, 2012). The crucial question is then what portions or aspects of the sport has to be electronic and / or computer-mediated for a sporting activity to be counted as an eSport. We argue that the main difference between a sport and an eSport comes down to where the player or team activities that determine the outcomes of the sport/play are manifested. In traditional sports, all outcome-defining activities can be seen to happen in 'the real world', even though the sport's practitioners may employ electronic and computerized systems to aid the sporting activities. However we observe and argue that in eSports, the outcome-defining activities happen in a 'virtual world' ${ }^{\mathrm{i}}$, or in other words within electronic/digital/computer-mediated 
What is eSports and why do people watch it?

environments. The outcome-defining activities are coordinated, orchestrated and operated by human beings in the 'real world', however it is not the physical and practical circumstance that the player inhabits that ultimately defines the outcome of play, but rather the system states that exist within the confines of the electronic system (which is controlled by the player and governed by the rules of the eSport's software and technology). Given that the playing humans occupy the 'physical world', but the outcome-defining events of eSports happen in the 'virtual world', then eSport athletes are always required to use or otherwise interact with a human-computer interface that connects their bodies to the electronic system (See Table 1).

Table 1 Conceptualizing the difference between sports and eSports

\begin{tabular}{llll}
\hline & $\begin{array}{l}\text { What space } \\
\text { does the } \\
\text { athlete } \\
\text { occupy? }\end{array}$ & What sporting equipment do the athletes primarily use? & $\begin{array}{l}\text { 'Where' do the } \\
\text { outcome-defining } \\
\text { events happen? (field } \\
\text { of play) }\end{array}$ \\
\hline eSports & $\begin{array}{l}\text { The 'real } \\
\text { world' }\end{array}$ & $\begin{array}{l}\text { Human-computer interface (Human input: e.g. mouse, } \\
\text { keyboard, EEG, microphone, motion sensors, weight sensors, } \\
\text { acceleration sensors. Computer output: e.g. display devices, } \\
\text { haptic feedback, audio devices.) }\end{array}$ & $\begin{array}{l}\text { Within electronic } \\
\text { systems }\end{array}$ \\
Sports & $\begin{array}{l}\text { Human-physical object interface or no sporting equipment } \\
\text { required }\end{array}$ & In the 'real world' \\
\hline
\end{tabular}

Based on these notions, we define eSports as a form of sports where the primary aspects of the sport are facilitated by electronic systems; the input of players and teams as well as the output of the eSports system are mediated by human-computer interfaces.

Spectating on eSports can be superficially seen as a similar activity to spectating on any sports. Most commonly, eSports are being consumed by watching live streams on the internet, where in addition to watching the event, spectators can participate in surrounding social interaction, for example in the form of chat features. As eSports are computer-mediated, spectating can never be without computer-mediated aspects as spectators watching an eSport event 'live' have to eventually watch events from a computer-output such as a video screen or a monitor. 
What is eSports and why do people watch it?

As previously mentioned, literature on eSports is still rare and dispersed, and most of this body of literature has focused on the qualitative documentation of visible phenomenon in tournaments (e.g. Carter and Gibbs, 2013; Cheung and Huang, 2011; Hutchins, 2008; Seo and Jung, 2014; Seo, 2015; Taylor, 2012a; Taylor, 2012b; Wagner, 2006; Witkowski, 2009; Witkowski, 2012). Published quantitative research on the questions of why people watch eSports or why players wish to attend eSports events is, as of yet, non-existent. Thus far, only one study has been published on the reasons for watching eSports (Weiss and Schiele, 2013), and it finds that competition, challenge and escapism were positively associated with eSports use. However, the study measured the general motivational aspects related to playing video games, and thus it makes it extremely difficult to compare the results to other works on media viewing. Other qualitative literature suggests that the reasons for eSports consumption should in principle correspond to those of traditional sports. For example, based on an interview study, Cheung and Huang (2011) remarked that eSports consumption motivations fairly well correspond to those of traditional sports (using the MSSC scale of Trail \& James, 2001). However, given that their study was qualitative in approach, there was no way to infer how salient the different motivations were, or how associated they might be with frequency in eSports consumption. Therefore, in order to continue the research on eSports consumption motivations, we have specifically employed the MSSC measurement instrument in measuring the motivations of eSports spectators, and also which of these motivations can be used to predict eSports watching frequency.

\subsection{The motivations for eSports consumption}

The research on sports consumption like any other media and media content research is primarily focused on the motivations of why people consume it, how they consume it, as well as what kinds of needs the given form of media might gratify. Sports consumption research has mostly been conducted in the academic area of sports management, however, with the rise of eSports, sports are increasingly to be seen as a computer-mediated form of media. This is especially the case not only 
What is eSports and why do people watch it?

because sports media content is conveyed through computerized broadcasting such as streams on the internet, but because the entire sporting activity is also computer-mediated. In eSports, the actions of players and teams are manifested in electronic computer-mediated systems. These aspects of eSports make sports an increasingly interesting subject of media study, and also for the study of (computer-mediated) communication.

In the area of communication and media research, the uses and gratification theory (UGT) framework is perhaps the most commonly adopted perspective which has been used to analyze media consumption (Katz et al., 1974; Katz et al., 1973; Wang et al., 2008; West and Turner, 2010). UGT has especially been used within research in online contexts (LaRose and Eastin, 2005; Papacharissi and Mendelson, 2010; Papacharissi and Rubin, 2000; Whiting \& Williams, 2013), including online games (Wu et al., 2010), Facebook (Joinson, 2008), video streaming (Cha 2014, Chiang, and Hsiao, 2014; Sjöblom and Hamari, 2016), Twitter (Johnson and Yang, 2009; Chen, 2011), and fantasy sports (Farquhar and Meeds, 2007). Uses and gratifications theory (UGT) is a theoretical approach to understanding why and how people consume or use different kinds of media to satisfy different kinds of needs. UGT is specifically focused on understanding media consumption from the perspective of the individual rather than the media type. To this end, UGT considers individuals as conscious of their own consumption, and also that media competes for gratification with other sources (Katz et al., 1974).

Similarly, in research on sports consumption, the two most widely adopted measurement scales are the Motivation Scale for Sports Consumption (MSSC) and the Sports Fan Motivation Scale (SFMS: see Wann, 1995; Wann et al., 1999). For this study we chose to use the MSSC over the SFMS, as the items belonging to the MSSC were general enough to be applicable to the context of eSports. Additionally, as this study aims to predict media consumption, the MSSC items were seen as a better fit as they did not include the dependent variable in the item. For example, the SFMS includes the statement "One of the main reasons that I watch, read, and/or discuss sports is that 
What is eSports and why do people watch it?

doing so gives me the opportunity to temporarily escape life's problems", whereas a similar item in the MSSC stated "The game provides an escape from my day-to-day routine". The MSSC relies on a similar theoretical understanding as the UGT, in that it focuses on the gratification and experiences that sports consumption affords for spectators. The MSSC (and other related instruments) and UGT share many mutual aspects, such as an escapism from everyday life, acquiring information from the media content, being a fan, social interaction and so forth. Therefore, both the theoretical understanding and most of the constructs between these areas are directly compatible with research on media consumption motivations in the media and communication areas.

In this paper we apply the MSSC for measuring eSports consumption motivations. By doing so we can be confident that our results are not only comparable with media consumption research as a whole, but also it enables us to make direct comparisons between eSports consumption motivations and the motivations to consume traditional sports. Therefore, in this study, we rely on the motivation scale for sports consumption as both our theoretical approach as well as the basis for our measurement of the phenomenon.

The MSSC has gone through some revisions, and has resulted in current variations which commonly consist of 8-10 constructs (Fink et al., 2002; Trail et al., 2000; Trail and James, 2001), including vicarious achievement, aesthetics of sport, drama of sport, watching sports as a means to escape everyday life, knowledge acquisition related to the sport, admiring the skills of the athlete's, social interaction with other spectators, physical attractiveness of the athletes, novelty of new players and teams, and the enjoyment of aggression and the aggressive behaviors the athletes exhibit.

Vicarious achievement refers to empathizing and co-living with people and characters in media content, and in the sports context, with the achievements of teams and players (Cialdini et al., 1976; 
What is eSports and why do people watch it?

Cialdini and Richardson, 1980; Krohn et al., 1998; Smith, 1988; Trail et al., 2000; Wann, 1995). As such, vicarious achievement has a strong social component, as it relates closely to feeling a sense of community and belonging with the players and teams the spectator is rooting for. In eSports, professional players can be more easily approachable than those in their physical counterparts - for example in soccer. Due to the fact that many professional players are also active streamers, this allows for an easy channel of communication between the spectators and professional players. We argue that this factor may allow for a deeper connection between spectators and the players and teams they follow, thus leading to a higher sense of vicarious achievement. Many eSport games actively involve the professional players in the form of fan merchandise and similar products which may be linked to a large tournament. Therefore, we hypothesize that vicarious achievement is positively associated with eSports watching frequency $(\boldsymbol{H 1})$.

The aesthetic aspects of the sports refer to the elements of beauty or gracefulness which are inherent in the sport (Trail \& James 2001). Visual elements have been shown to be important motivational factors in spectator sports (Wann et al., 1999; Wann and Wilson, 1999; Krohn et al., 1998; Smith 1988). Studies have shown that sports that are scored such as gymnastics or figure skating, attract viewers that rate aesthetic motivations highly (Bryant et al., 1981; Sargent et al., 1998; Zillmann, 1995). Within the realm of eSports, previous research has discussed eSports events as aesthetic experiences on a more holistic level (Seo, 2013), characterized as "a transcendent character built of liminoid elements and consumer fantasy" (Kozinets et al., 2004, p. 658).

Within the realm of media research, affective motivations have been shown to impact use in the contexts of eSports (Cheung and Huang, 2011), video game streaming (Hamilton et al., 2014), social media (Papacharissi and Mendelson, 2010; Whiting and Williams, 2013) and video sharing websites (Cha, 2014; Hanson and Haridakis, 2008). Accordingly, we hypothesize that an appreciation of the aesthetic aspects of eSports is positively associated with eSports watching frequency $(\boldsymbol{H} 2)$ 
What is eSports and why do people watch it?

Within the realm of eSports, we can separate aesthetic gratification into two distinct categories: the players and the game. The physical attractiveness construct refers to the appreciation of the appearance of people and characters in media, and in the sports context, viewing the players involved in the game, and the degree to which the spectator finds the players physically attractive (Duncan and Brummett, 1989; Guttmann, 1996). As the main play of eSports happens in the confines of electronic systems, one could easily and intuitively assume that the physical appearance of the players would not be an important or visible aspect in eSports. However, most of the recordings and broadcasts of eSports events record videos of the players before, during and after matches. While video game players have been anecdotally believed to be physically unfit and unkempt young men, many top eSports athletes are often in fact physically fitter than the average person. Many eSports players' interviews reflect the belief commonly held in the eSports scene that physical fitness and activity stimulates and maintains cognitive facilities and hand-eye coordination. Therefore, the fitness of eSports players might not be nearly as far-fetched as the anecdotal beliefs might suggest. Therefore, we hypothesize that the physical attractiveness of players is positively associated with eSports watching frequency $(\boldsymbol{H 3})$.

The drama construct refers to the enjoyment of uncertainty and dramatic turns of events in media content such as sports. Drama has been shown to be an important contributor to sports viewing in general (Raney and Depalma, 2006; Su-lin et al., 1997; Peterson and Raney, 2008). Within the area of eSports, drama is also an important element of the viewing experience as the same sense of uncertainty is present as in traditional sports. Many eSport games have added elements of randomness and information asymmetry built into them, thus further increasing the notion of uncertain outcomes (Cheung \& Huang, 2011). We hypothesize that drama is positively association with eSports watching frequency $(\boldsymbol{H 4})$.

Escapism refers to the degree to which media enables an escape from day-to-day routines, and provides a distraction from everyday activities. Escape has been shown to be of significant impact 
What is eSports and why do people watch it?

for viewing sports, and unlike other forms of emotional motivations, the escape motivation is less dependent on the actual outcome of the game (Gantz, 1981; Gantz and Wenner, 1991; Gantz and Wenner, 1995; Krohn et al., 1998; Wann, 1997; Wenner and Gantz, 1998; Wann and Rochelle, 1999; Wann et al., 2008). Escape has also been shown to be a strong motive for use within prior research on uses, motivations and gratification related to media viewing (Lin, 2002; Papacharissi and Mendelson, 2010; Whiting and Williams, 2013). We believe eSports may be rather similar in terms of providing a means of escape as other forms of media and sports. eSports might provide a more accessible form of escape when compared to traditional media and sports. Therefore, we hypothesize that escapism is positively association with eSports watching frequency (H5).

The acquisition of knowledge construct refers to the degree of which media consumption enables an acquisition of knowledge. In traditional sports, two important cognitive motivations for spectating have been learning about the players and teams (Gantz and Wenner, 1995; Wenner and Gantz, 1998), and collecting information to be shared in conversations about the sport (Karp and Yoels, 1990; Lever, 1993; Melnick, 1993). Within research on media use and media consumption, knowledge acquisition has been shown to be an important factor within video game streaming (Hamilton et al., 2014), social media (Papacharissi and Mendelson, 2010; Whiting and Williams, 2013), and internet use (Courtoiset al., 2009; Ebersole, 2000; Papacharissi and Rubin, 2000). In eSports, video games the strategies and tactics are readily copied and reproduced since the sporting activities do not have as many prerequisite abilities as traditional sports. We hypothesize that acquiring knowledge is positively association with eSports watching frequency $(\boldsymbol{H 6})$.

Related to the acquisition of knowledge; as the large proportion of eSports spectators play some the same games themselves, we believe they possess the experience and facilities to appreciate, understand and admire the skills the professional players exhibit. Therefore, we hypothesize that appreciation of player skills is positively association with eSports watching frequency $(\boldsymbol{H} 7)$. An 
What is eSports and why do people watch it?

appreciation of player skill has been shown to be an impactful motivational factor in sports (Milne \& McDonald, 1999).

The social interaction construct refers to the gratifications related to socializing with other media consumers. Socializing with peers has been shown to be of great importance in traditional sports (Dietz-Uhler et al., 2000; Eastman and Land, 1997; Gantz, 1981; Gantz and Wenner, 1991; Melnick, 1993), and also within eSports and playing video games (Hamilton et al., 2014; Sherry et al., 2006). In the context of media usage research, social interaction has also been shown to be of great importance (Chen, 2011; Hamilton et al., 2014; Pai and Arnott, 2013; Papacharissi and Mendelson, 2010; Sjöblom and Hamari, 2016; Whiting and Williams, 2013). eSports spectating is commonly connected to an online chat that can be used to comment on the events of the game, and also as a way to cheer for favorite teams and players. As much of the eSport consumption takes place online, is it natural to assume that bonds are created between people through computermediated means. It is worth noting that due to the technological nature of many services through which eSports is consumed, many simultaneous social groups and actors can coexist in one space, each possibly performing separate action (Woerman and Kirschener, 2015). We hypothesize that social interaction is positively association with eSports watching frequency (H8).

Gratification related to novelty in the sporting media refer to the enjoyment and excitement related to seeing new players and teams in the sporting scene and is regarded as one of the main factors of sports consumption (Trail and James, 2001). As eSports has not yet had much time to mature as an industry, there are relatively few established teams and games that are being played. Thus there is a constant influx of new talent and the scene is constantly evolving. Therefore, we hypothesize that novelty is positively association with eSports watching frequency (H9).

Aggressive behavior is a common part of many veins of today's media, and particularly in sports. The enjoyment of aggression refers to the enjoyment derived from witnessing aggressive behavior, 
What is eSports and why do people watch it?

macho attitudes and the hostility exhibited by the players. Previous research has found that a preference towards aesthetics significantly impacts the enjoyment and consumption of sports which are classified as aggressive (Wann et al., 1999; Wann et al., 2008; Wann and Wilson, 1999). As the main play of eSports happens in the confines of electronic systems, one could intuitively assume that physical aggression would not be as important or visible aspect in eSports. However, most of the recordings and broadcasts of eSports events video the players before, during and after matches. In fact, it is a rather common (but a frowned upon phenomenon) for players to exhibit aggressive behavior, by for example by banging the table at which they are playing. Therefore, we hypothesize that aggressive behavior is positively association with eSports watching frequency (H10).

Table 2 Sports consumption motivation constructs (adapted from Trail \& James, 2001; Trail, 2012)

\begin{tabular}{|c|c|c|c|}
\hline Construct & ID & Items & Definition \\
\hline $\begin{array}{l}\text { Vicarious } \\
\text { achievement }\end{array}$ & VA & 3 & $\begin{array}{l}\text { Empathizing and co-living the achievements of teams and players the } \\
\text { spectator is emotionally attached to }\end{array}$ \\
\hline Aesthetics & AES & 3 & The appreciation of the beauty and gracefulness inherent in the sport \\
\hline Drama & DRA & 4 & $\begin{array}{l}\text { The enjoyment of the drama, uncertainty and dramatic turns of events in } \\
\text { the sports }\end{array}$ \\
\hline Escape & ESC & 3 & $\begin{array}{l}\text { The degree to which watching the sport enables an escape from day-to- } \\
\text { day routines and provides distraction from everyday activities }\end{array}$ \\
\hline $\begin{array}{l}\text { Acquisition of } \\
\text { knowledge }\end{array}$ & KNO & 3 & $\begin{array}{l}\text { The degree to which watching the sport enables the acquisition of } \\
\text { knowledge related to the game, its strategies and other technical aspects }\end{array}$ \\
\hline $\begin{array}{l}\text { Skills of the } \\
\text { players/athletes }\end{array}$ & SKI & 3 & $\begin{array}{l}\text { The enjoyment of witnessing the high skill that players exhibit and well- } \\
\text { executed performances in the sport }\end{array}$ \\
\hline Social interaction & $\mathrm{SOC}$ & 3 & $\begin{array}{l}\text { The enjoyment related to interacting and socializing with other people } \\
\text { watching the game }\end{array}$ \\
\hline $\begin{array}{l}\text { Physical } \\
\text { attractiveness }\end{array}$ & ATTR & 3 & $\begin{array}{l}\text { The enjoyment related to and the degree to which the spectator finds the } \\
\text { players physically attractive }\end{array}$ \\
\hline Novelty & NOV & 3 & $\begin{array}{l}\text { The enjoyment and excitement related to seeing new players and teams in } \\
\text { the sporting scene }\end{array}$ \\
\hline $\begin{array}{l}\text { Enjoyment of } \\
\text { aggression }\end{array}$ & AGGR & 4 & $\begin{array}{l}\text { The enjoyment derived from witnessing the aggressive behavior, macho } \\
\text { attitudes and hostility exhibited by players }\end{array}$ \\
\hline
\end{tabular}


What is eSports and why do people watch it?

\section{The empirical study}

\subsection{Data}

The data for this study was gathered via an online survey administered amongst people who watch eSports on the Internet. Before administering the survey, we piloted $(n=20)$ the survey in order to acquire both feedback on whether taking the survey presented any problems to the respondents as well as to explore the validity of measurement. No major problems were observed in the pilot study concerning the measurement of sports consumption motivations. After the pilot, the link to the survey was spread over variety of international internet channels related to eSports and internet game streaming such as related Reddit, Facebook, Twitter and forum subgroups. According to our estimates the respondents arrived to the survey from the following websites: $70-75 \%$ eSports related subreddits, $10-15 \%$ Twitter, 5-10\% Facebook and 5-10\% other sites and direct traffic (we employed a couple of different links to gather respondents. All links did not have tracking for the traffic source, and therefore, we only have an estimate). The survey was available online from February $26^{\text {th }} 2015$ until the $23^{\text {rd }}$ of March 2015 during which 888 usable answers were received. As a participatory incentive, we raffled six gift certificates (worth 50 USD or 50 EUR) to the Steam game store among valid responses. Table 3 outlines the demographic details of the respondents.

Table 3 Demographic distribution of survey

\begin{tabular}{llllll}
\hline & & $\mathrm{n}$ & & & $\mathrm{n}$ \\
\hline Age & 15 or less & 35 & Education & None & 1 \\
& $16-20$ & 333 & & Primary / elementary & 83 \\
& $21-25$ & 267 & & Secondary & 471 \\
& $26-30$ & 164 & Higher & 355 \\
\cline { 3 - 5 } & $31-35$ & 67 & Employment & Full-time & 197 \\
& $36-40$ & 18 & 4 & Part-time & 519 \\
& 41 or more & 22.75 & Student & 83 \\
& Mean & 22 & & Unemployed & 1 \\
& Median & & & Retired & 13 \\
\hline Gender & Female & 63 & Other & 9 \\
& Male & 825 & & Never (more rarely than yearly) & 34 \\
& & & Yearly (once a year) & 140 \\
& & & Monthly (once a month) & 402 \\
& & & Weekly (once a week) & 303 \\
\hline
\end{tabular}


What is eSports and why do people watch it?

\subsection{Measurement}

The measurement consisted of The Motivations Scale for Sports Consumption (MSSC) (Trail \& James, 2001). The scale was measured on a 7-point Likert scale from "Strongly disagree" to "Strongly agree" as specified by the instrument. Originally the MSSC consisted of nine constructs: vicarious achievements, aesthetics, drama, escape, knowledge, skills, social interaction, physical attractiveness, and family. However, the MSSC has been modified slightly since its inception with the deletion of the family subscale and a rewording of the escape subscale (Fink et al., 2002). The family subscale was removed from the MSSC because the original developers of the scale believed that the family dimension might be a byproduct of consuming sports, rather than a specific motivation (Trail, 2012). Moreover, we added scales for novelty and enjoyment of aggression constructs as suggested by Trail (2012). The dependent variable of the frequency of watching eSports had 5 options: “never”, “once a year”, “once a month”, “once a week”, “daily”.

\subsection{Validity and reliability}

The model-testing was conducted via the component-based PLS-SEM (Partial Least Squares Structural Equation Modeling) which is considered to be more suitable for prediction-oriented studies such as the present study, whereas co-variance-based SEM is seen as being better suited to testing which models best fit the data (Anderson and Gerbing, 1988; Chin et al., 2003). Moreover, many previous studies have already assessed the model fit (see e.g. Funk and James, 2006; James amd Ridinger, 2002; Robinson et al., 2004; Robinson and Trail, 2005; Seo and Green, 2008; Trail and James, 2011; Won and Kitamura, 2007). Convergent validity was met since the AVE, CR and Alpha measures exceeded the recommended thresholds (Fornell and Larcker, 1981; Nunnally, 1978). Discriminant validity was met since the square root of the AVE of each construct was larger than its correlation to any other construct (Chin, 1998; Fornell and Larcker, 1981; Jöreskog and Sörbom, 1996), and each measurement item had the highest loading with its corresponding construct. 
What is eSports and why do people watch it?

Table 4 Validity and reliability

\begin{tabular}{|c|c|c|c|c|c|c|c|c|c|c|c|c|c|c|}
\hline & AVE & CR & Alpha & $\mathbf{0}$ & 1 & 2 & 3 & 4 & 5 & 6 & 7 & 8 & 9 & 10 \\
\hline $0 \mathrm{WATCH}$ & 1.000 & 1.000 & 1.000 & 1.000 & & & & & & & & & & \\
\hline $1 \mathrm{VA}$ & 0.932 & 0.820 & 0.891 & 0.206 & 0.905 & & & & & & & & & \\
\hline 2 AES & 0.911 & 0.772 & 0.863 & 0.090 & 0.413 & 0.879 & & & & & & & & \\
\hline 3 DRA & 0.900 & 0.692 & 0.851 & 0.214 & 0.350 & 0.454 & 0.832 & & & & & & & \\
\hline 4 ESC & 0.945 & 0.852 & 0.913 & 0.220 & 0.418 & 0.319 & 0.328 & 0.923 & & & & & & \\
\hline $5 \mathrm{KNO}$ & 0.917 & 0.788 & 0.865 & 0.277 & 0.369 & 0.471 & 0.543 & 0.270 & 0.887 & & & & & \\
\hline $6 \mathrm{SKI}$ & 0.906 & 0.763 & 0.844 & 0.257 & 0.326 & 0.456 & 0.667 & 0.258 & 0.717 & 0.873 & & & & \\
\hline $7 \mathrm{SOC}$ & 0.957 & 0.882 & 0.933 & 0.107 & 0.400 & 0.334 & 0.250 & 0.285 & 0.283 & 0.245 & 0.939 & & & \\
\hline 8 ATTR & 0.873 & 0.696 & 0.795 & -0.033 & 0.191 & 0.165 & -0.032 & 0.185 & 0.025 & -0.076 & 0.228 & 0.835 & & \\
\hline $9 \mathrm{NOV}$ & 0.940 & 0.840 & 0.905 & 0.226 & 0.451 & 0.497 & 0.478 & 0.324 & 0.514 & 0.478 & 0.394 & 0.135 & 0.917 & \\
\hline 10 AGGR & 0.879 & 0.647 & 0.819 & 0.196 & 0.396 & 0.331 & 0.305 & 0.318 & 0.240 & 0.206 & 0.283 & 0.243 & 0.381 & 0.804 \\
\hline
\end{tabular}

Bolded figures on the diagonal are square rooted AVEs

\subsection{Results}

We investigated which motivational factors would predict the frequency of watching eSports. The results (Table 5) indicated that escaping everyday life (H5 $0.131 * *$ ), acquiring knowledge from eSports (H6 0.165**), novelty (H9 0.076*) and the enjoyment of aggression (H10 $\left.0.117^{* *}\right)$ were positively and statistically significantly associated with the frequency of watching eSports. The results pertaining to novelty should, however, be interpreted with caution as indicated by the low Beta and confidence intervals. Interestingly, the results also show that the enjoyment of aesthetic aspects of eSports $(\mathrm{H} 2-0.157 *)$ is negatively associated with the frequency of watching eSports. There were no statistically significant associations between the rest of the motivations and the frequency of watching eSports. However, when more closely examining the Betas and confidence intervals, it can be interpreted that the skills of the players might also have a small positive association with the frequency of watching eSports. 
What is eSports and why do people watch it?

Table 5 Results, $*=\mathbf{p}<0.01, * *=\mathbf{p}<0.001$

\begin{tabular}{|c|c|c|c|c|c|c|c|}
\hline & & Model - & $\mathrm{v}$ : eSports & atching fre & uency $(\mathrm{R}$ & $=0.139)$ & \\
\hline $\mathrm{H \#}$ & IV & $\mathrm{B}$ & CI99 low & CI90 low & CI90 hi & CI99 hi & $\mathrm{p}$ \\
\hline 1 & Vicarious achievement & 0.068 & -0.047 & -0.005 & 0.132 & 0.173 & 0.114 \\
\hline 2 & Aesthetics & $-0.157 * *$ & -0.240 & -0.206 & -0.084 & -0.000 & 0.000 \\
\hline 3 & Physical attractiveness & -0.076 & -0.167 & -0.138 & 0.045 & 0.094 & 0.161 \\
\hline 4 & Drama & -0.004 & -0.136 & -0.087 & 0.086 & 0.137 & 0.938 \\
\hline 5 & Escape & $0.131^{* *}$ & 0.034 & 0.072 & 0.189 & 0.217 & 0.000 \\
\hline 6 & Acquisition of knowledge & $0.165 * *$ & 0.030 & 0.080 & 0.245 & 0.298 & 0.001 \\
\hline 7 & Skills of the players/athletes & 0.096 & -0.067 & -0.007 & 0.194 & 0.261 & 0.125 \\
\hline 8 & Social interaction & -0.021 & -0.111 & -0.082 & 0.039 & 0.074 & 0.567 \\
\hline 9 & Novelty & $0.076^{*}$ & -0.042 & 0.001 & 0.148 & 0.179 & 0.079 \\
\hline 10 & Enjoyment of aggression & $0.117 * *$ & 0.022 & 0.057 & 0.171 & 0.207 & 0.001 \\
\hline
\end{tabular}

\section{Discussion}

During recent years, eSports (electronic sports) and video game streaming have become rapidly growing forms of new media in the internet driven by the growing provenance of (online) games and online broadcasting technologies. Today, hundreds of millions of people spectate eSports. The present investigation presented a seminal study on gratification-related determinants of why people spectate eSports on the internet. Moreover, the study proposed a definition for eSports and further discussed how eSports can be seen as a form of sports. We defined eSports as a form of sports where the primary aspects of the sport are facilitated by electronic systems; the input of players and teams as well as the output of the eSports system are mediated by human-computer interfaces.

The main portion of the study focused on measuring eSports consumption motivations and analyzing which motivations were associated with the frequency of watching eSports $(\mathrm{N}=888)$. Beyond the supported hypotheses (H5, H6, H9, H10) surprising results afford more elaboration and discussion.

The results showed that the enjoyment of the aesthetic aspects of eSports was negatively associated with a frequency in watching eSports. The video games being played in eSports are usually complex and require a considerable amount of concentration to comprehensively follow the game. Therefore, we believe that admiring the aesthetic aspects of the game whilst concurrently with keeping up with the nuances of occurrences during the game may be practically difficult. Therefore, 
What is eSports and why do people watch it?

those viewers who focus more on the aesthetic aspects may have a wholly different experience to those viewers who focus on the technical and rule-based proceedings of the sport. Perhaps this approach to viewing may turn spectators away from most eSports since their understanding of the game may remain limited. For example, in the context of gymnastics it has been shown that an appreciation of the aesthetic aspects of the sport positively impact viewing (Sargent et al., 1998). However, we argue that gymnastics performances are split into smaller portions than typical eSports performances. Therefore, it is easier for the viewer to concentrate on the inherent beauty of the performance, as there are no ancillary activities taking place. Therefore, the dynamics between aesthetic appreciation and consumption could prove to be a fruitful area for future research. Further studies could compare eSports that are performed in smaller chunks and those that are longer and more tactically complex to follow.

In the results. drama does not seem to be significantly associated with spectators' eSports watching frequency. This finding seem to be contrary to previous qualitative observations where the importance of drama and information asymmetry have been highlighted (Cheung and Huang, 2011). Additionally, within the realm of video game streaming, dramatic turn of events have been argued to increase viewership (Karhulahti, 2016). Many popular eSports games employ an amount of information asymmetry to create strategic tension between players, and also dramatic tension for players. For example Starcraft 2 has an element called fog of war, which obscures parts of the map for players (Cheung and Huang, 2011). The actions showed to spectators is free of this fog of war, but the director of the broadcast has the ability to choose what to show and what to hide. This can be used to create dramatic tension by, for example, hiding a looming ambush, only to focus on that part of the map at the very last second, creating an exhilarating experience for spectators. Due to this prevalence of dramatic elements, it is interesting to see the lack of association of drama with spectating frequency in the present results. 
What is eSports and why do people watch it?

The lack of a meaningful association of drama and spectating frequency could perhaps be further explained by the diminishing return nature of drama. For example, in soccer it is considered a dramatic turn of events if a team manages to even the score against exceptional odds, or in a virtual scenario such as Counter-Strike (an online first-person shooter game), for a single player to defeat an entire opposing team singlehandedly. A first or second extraordinary play might excite the spectator and provide a motive for spectating, but if almost every game contains an event perceived to be either a one-off or spectacular, then the excitement might not continue. Therefore, although players who watch a lot of eSports might appreciate drama and see it as a necessary motivation for viewing, it does not dictate their viewing habits. As would stand to reason, drama is expected to be fairly evenly distributed across matches and viewers who watch a lot of eSports during a certain time period have a higher expectancy to see drama unfold within the games. However, few studies have quantitatively investigated the relationship of drama gratification and spectating frequency (Peterson and Raney, 2008; Raney and Depalma, 2006). Therefore, the aspect of diminishing returns on the impact of dramatic turns of events in media could also provide an interesting further line of study. One way to study the effects of the diminishing nature of drama in a media content might be to devise an experiment involving content with varying levels of dramatic events, similar to research that has been done to study perceived aggression in sports (Bryant et al., 1982; Comisky et al., 1977; Raney and Depalma, 2006).

The correlation between perceived played skill and watching frequency was small and statistically insignificant, although slightly positive. Perhaps this small effect could be explained by player skill being seen as a form of hygiene factor. That is to say, a certain threshold for player skill needs to be present in order for the match to have a perceived relevance, but beyond this effect, player skill does not seem to increase the watching frequency. Within the present dataset we were unable to differentiate between the different levels of skill shown in the eSports that respondents consumed. Further studies could more meticulously measure what types of eSports respondents consumed, and 
What is eSports and why do people watch it?

on which skill levels (e.g. amateurs vs. professionals). This would allow further investigation into differences in effect between the appreciation of player skill and the enthusiasm to consume eSports.

Previous qualitative and anecdotal observations are canonical on the importance of social interaction in watching streams and eSports (Cheung and Huang, 2011; Hamilton et al., 2014;

Scholz, 2012; Seo, 2013; Sherry et al., 2006; Sjöblom and Hamari, 2016; Trepte et al., 2012; Woerman and Kirschener, 2015). It is easy to subscribe to these conceptions as social interaction and functionalities are clearly present in services that are used for spectating. However, our quantitative results (and the quantitative results related to eSports playing in Weiss and Schiele 2013) on whether social gratification affect spectating frequency indicate otherwise, as there was no significant effect to be found. This would imply that the social dimensions of spectating are less important than previous research would lead us to believe, at least when it comes to factors affecting watching frequency. A finding of this nature for eSports is indeed highly interesting, as traditional sports is so strongly tied to social groups and social interactions.However, another interpretation is that the possibilities for social interaction provided by the services through which spectating is taking place are not affording the level of interaction needed to obtain adequate levels of gratification. So while spectators might be interacting with others through social media, forums and chat, this form of online social interaction may not afford the same level of social gratifications as co-located social interaction might. Therefore, investigating eSports spectating gratification in an on-site spectating circumstance may show different levels of gratification.

As initially hypothesized, enjoying the aggressive behaviors exhibited by the eSports athletes was positively and significantly associated with watching frequency. These findings are especially interesting in the context of eSports since the athletes are not directly presented during the actual eSports games, and the broadcast content therefore shows the physical bodies of athletes less than in say traditional track and field sports. However, the athletes themselves appear on screen during 
What is eSports and why do people watch it?

broadcasts of eSports tournaments during breaks between games, and when pre-filmed footage is shown in storytelling sequences. We argue that at least partially the enjoyment of aggression stems from the rivalries existing between eSports teams and players, perhaps a milder form of aggression that we are used to seeing in traditionally sports. On the other hand, many eSports games are at their core violent in their imagery, for example Counter-Strike: Global Offensive where shooting your opponents is part of the core game. This is the other type of aggression that can be seen as a motivating factor for consumption.

While the body of literature on eSports and game stream consumption motivations specifically has only started to appear (including the present study), there is an ample body of literature on reasons why people play games themselves. While watching others play (and in the context of this paper: spectating electronic sports) is not the exact same activity as playing games oneself, the phenomena undoubtedly have overlap as both consist of consuming (video) game-related content. Therefore, comparing the results of this study to those studies that have been conducted on the factors that predict gaming activities can be considered fruitful and may provide further lines of inquiry also to the study of consumption motives of eSports. The studies investigating factors that may affect quality and quantity of playing video games can be roughly divided into three main categories based on the selection of determinant they investigate. The first category is concerned with player types (Bartle 1996; Hamari and Tuunanen, 2014), mentalities and orientations (Kallio et al., 2011). The second vein of literature on this area is more directly focused on motivations and gratification as predictors of playing activities (e.g. Chang et al., 2014; Davis et al., 2013; Hamari et al., 2015b; Hamari and Koivisto, 2015; Huang and Hsieh, 2011; Lu and Wang 2008; Wei and Lu, 2014; Yee, 2006). Finally, the third category is focused on the demographic and other background factors of players (Hamari and Lehdonvirta 2010; Janz et al., 2010; Koivisto and Hamari, 2014; Mäyrä et al., 2016; Williams et al., 2008; Yee, 2006b). To these bodies of literature on gaming motivations, the present study introduces the perspective of watching games being played as a form of gaming activity. Furthermore, 
What is eSports and why do people watch it?

the present study lays its roots also to the opposite direction; it brings game research pursuits into the sports research arena by defining and investigating how eSports (competitive video gaming) can indeed be seen as a sport. Through these conceptual and disciplinary unions, the study also brings the notion of how watching games being played can be viewed from the perspective of sports consumption, a previously little explored view in game research area (although previously suggested by e.g. Cheung and Huang, 2011).

In the player type-related research (See e.g. Bartle, 1996; Hamari and Tuunanen 2014; Yee, 2006a), players have been customarily divided into achievement, immersion/exploration, social and competition -oriented players. In future research on eSports consumption these player typologies could be applied in investigating whether eSports consumption motivations and habits differ in accordance to the spectators' gaming orientations. A large portion of the research investigating more detailed motivations have seemingly focused on technology acceptance (See e.g. Davis, 1989; van der Heijden, 2004) of games and specifically on both utilitarian and hedonic motivations of playing (Chang et al., 2014; Davis et al., 2013; Hamari et al., 2015b; Hamari and Koivisto 2015). In the present study many of the investigated factors represent more hedonically oriented dimensions of spectating sports. The present study did not measure many, what can be seen as, utilitarian or instrumental motivations to watch eSports other than the motivation to acquire information from spectating eSports. Our results, as the results in the body of literature on games, highlight that consuming game content is not necessarily a purely hedonic pursuit even though games are often regarded as purely hedonic media. On the contrary, watching eSports may also provide information which can be useful for, for example, deciding which games to purchase or for eSports-related gambling. Beyond spectating eSports, being a professional eSports player or a professional video games streamer (See e.g. Hamilton et al., 2014; Jonasson and Thiborg, 2010; Seo, 2013; Sjöblom and Hamari, 2016) is a job which connects the phenomenon to an interesting view of playing games: playing video games can also take the form of work. Therefore, eSports affords a highly interesting 
What is eSports and why do people watch it?

phenomenon from the perspective of labor, work psychology and business ecology. In prior literature, playing games have been framed in the work context for example in the research veins on gamification (Hamari, 2013; Hamari et al., 2015a; Jung et al., 2010; Nelson, 2012; Morschheuser et al., 2016), gold farming/real-money-trade (e.g. Heeks, 2008; Lehdonvirta, 2005; Lehdonvirta and Castronova, 2014; Nakamura, 2009) and obviously poker and other forms of gambling (with varying skill-luck degrees) which represent forms of 'playing' connected to the intentional pursuit of income.

While the present study did not seek to investigate demographic factors in eSports per se, a clear majority of respondents in our data were males below 25 years of age. This may be an indication of the gender and age distribution in the general eSports fan community. However, in order to rigorously investigate the demographic distribution in the eSports community, further studies with wider samples should be conducted. Popular discussion does connect game consumption to adolescent males, however, recent literature (e.g. Mäyrä et al., 2016; Williams et al., 2006; Yee, 2006a) challenges this view. Today's surveys paint a broader, more inclusive picture; research shows that gaming is more equally distributed across genders and age groups. However, differences remain as to what types and genres of games different demographic groups gravitate towards (Mäyrä et al., 2016). As most current eSports games appear to represent entries on the more hardcore competition driven end of the spectrum, it could explain the young male majority in the fan base of eSports.

\subsection{Practical implications}

This study focused on investigating which motivations may predict the frequency of watching eSports (Table 5). For practitioners the results of this inquiry provide insights for further development of eSports-related services such as broadcast content, eSports community tools, eSports gambling -related service and so forth. The results of the study highlight gratifications that are more likely to increase eSports-related consumption, and therefore, show to practitioners some 
What is eSports and why do people watch it?

of the different aspects of eSports that may be worth emphasizing in further development of eSports-related services. For instance, knowledge acquisition was found to be one of the positive determinants of eSports spectating. Therefore, actors working in the eSports ecology might direct resources to developing better ways for the spectators to acquire knowledge from the eSports broadcasts. In practice, this could for example take the form of developing more effective ways of displaying the game states by, for instance, clearer depiction of player positions on the play area and ways for the commentators to more easily demonstrate team strategies on an overlay or alternatively by affording more information about player career statistics.

Surprisingly, our results showed a negative association between aesthetic appreciation of eSports content and spectating frequency. This might imply that game developers of existing eSports titles should not necessarily feel a pressure to emphasize graphical fidelity of games if the appreciation of that fidelity does not increase spectatorship. Indeed, if we observe today's popular eSports games, we can notice that they do not necessarily adhere to or employ the latest graphics technologies but rather focus on simplicity and clarity of presentation and graphics (also in order for the games to run properly on multiple tiers of hardware). Conversely, however, the negative association that was found in this study could be an indication of unoccupied space for new kinds of eSports to appear where the aesthetic aspects would be in a more emphasized role. For instance, if we consider the breadth of existing traditional sports, we can immediately recall several sports that emphasize aesthetic aspects and beauty, such as figure skating, synchronized swimming or gymnastics. In other words, the essence of these sports stems from how the performance visually looks, which is impacted by the athlete's skill. In these sports, sports consumption research has found a positive impact of aesthetics on spectating (e.g. Bryant et al., 1981; Sargent et al., 1998; Zillmann, 1995). Analogous eSports seem to currently be missing from the variety of popular eSports available today which may indicate both that the negative association is attributable to the types of games being played in eSports today and that there may be room for a larger variety of eSports in the future. 
What is eSports and why do people watch it?

Gratifications related to seeing aggressive behaviors (such as hostility, intimidation and macho atmosphere) exhibited by the players was positively associated with spectating frequency. Interestingly, however, players themselves commonly have less screen time than their traditional sports counterparts, and therefore, possibly witnessing these aggressive behaviors is scarce. By showcasing rivalries between players and teams, as well as giving more screen time to players and not just the game taking place, more emphasis could be placed on these aspects of eSports. If we regard these findings more broadly, giving players more screen time may also facilitate the increased fulfilment of other gratifications such as fandom.

The results also revealed that novelty of new teams and players appearing on the scene may be important aspect of following eSports. This may indicate that stagnation of eSports ladders and tournaments may have negative effect on the overall experience. These findings may then imply that eSports ladder and tournament organizers may find it beneficial to guarantee a high level of liquidity in team and player transitions between league and/or tournament levels. Therefore, when organizing tournaments, finding a balance between fixed/invited teams and those who can climb up the ladder based on pure performance may prove to be a fruitful mix for the viewing experience.

\subsection{Limitations and future research directions}

As is commonplace with studies conducted via online surveys, the data is self-reported and the respondents are self-selected. Using self-reported data may affect the findings as the users responding are potentially more actively engaged with the service and therefore willing to participate in activities related to it. Thus, the results possibly disregard the perceptions and intentions of less active and unengaged users of the service. These issues could be addressed in future studies, as well as the reasons for not being/becoming involved in the service. Future research could combine survey data with actual usage data and proper experiments, in order to increase the robustness of research on the topic. 
What is eSports and why do people watch it?

In the present study we employed one of the most widely applied sports consumption measurement scale. However, it is possible that there is something in the nature of eSports that may make it significantly different from traditional sports with respect to consumption motivations. Therefore, it is possible that the measures used here do not completely capture the entire spectrum of motivations that might be relevant to the spectatorship of eSports. One indication of this in our results is the low effect size implying that there indeed may remain other factors that explain what motivates people to spectate eSports. Therefore, future studies could expand on the set of motivations beyond the traditional motivations commonly linked to sports consumption of traditional sports. Furthermore, it is also commonplace with quantitative studies that the results are reductionist and geared towards generalizable overall indications of the phenomenon. As the activity of spectating eSports and participating in the related community is a multifaceted phenomenon, it is expected and likely that participant motivation can be more complex if we were to investigate the phenomenon on a more granular and deeper level by using e.g. qualitative methods.

eSports spectating motivations and behaviors might differ based on which platform they are viewed on. Streaming services such as Twitch, Hitbox, Azubu and YouTube can have different service design even though the underlying content can however be similar, if not identical. As the user behavior of a certain service are shaped by other users, creating a culture distinct to that service, this may then in turn affect the behavior of users more greatly than the actual feature differences between similar services providing eSports content. Naturally services that offer eSports content in a pre-recorded format, such as YouTube, may have significant differences when it comes to user behavior and motivations. Therefore, one future research avenue is in investigating motivational and behavioral differences that may stem from the platforms streaming eSports.

As previously mentioned, there was no association found between social interaction and spectating frequency. This could prove to be different if investigated in the live context, that is to say when both 
What is eSports and why do people watch it?

the spectator and the eSport players are physically present in the same space. This might also increase the general aesthetic experience, as noted before in the context of eSports events (Seo, 2013).

\section{References}

Bartle, R. (1996), "Hearts, clubs, diamonds, spades: Players who suit MUDs", Journal of MUD research, Vol. 1 No. 1, 19.

Bryant, J., Brown, D., Comisky, P. W., \& Zillmann, D. (1982), “Sports and spectators: Commentary and appreciation", Journal of Communication, Vol. 32 No. 1, 109-119.

Bryant, J., Comisky, P., \& Zillmann, D. (1981), “The appeal of rough-and-tumble play in televised professional football”, Communication Quarterly, Vol. 29 No. 4, 256-262.

Carter, M., \& Gibbs, M. R. (2013), “eSports in EVE Online: Skullduggery, fair play and acceptability in an unbounded competition", in Proceedings of $8^{\text {th }}$ FDG Conference, Crete, Greece, 14-17 May, 2013, pp. 47-54.

Cha, J. (2014), "Usage of video sharing websites: Drivers and barriers", Telematics and Informatics, Vol. 31 No. 1, 16-26.

Chang, I-C., Liu, C-C., \& Chen, K. (2014), "The effects of hedonic/utilitarian expectations and social influence on continuance intention to play online games", Internet Research, Vol. 24 No. 1, 21-45.

Chen, G. M. (2011), "Tweet this: A uses and gratifications perspective on how active Twitter use gratifies a need to connect with others", Computers in Human Behavior, Vol. 27 No. 2, 755762.

Cheung, G. and Huang, J. 2011, "Starcraft from the stands: Understanding the game spectator", in Proceedings of the 2011 Annual Conference on Human Factors in computing systems (CHI'11), ACM, New York, NY, USA, 763-772.

Chiang, H. S., \& Hsiao, K. L. (2015), "YouTube stickiness: the needs, personal, and environmental perspective", Internet Research, Vol. 25 No. 1, 85-106.

Chin, W. W., Marcolin, B. L., \& Newsted, P. R. (2003), “A partial least squares latent variable modeling approach for measuring interaction effects: Results from a Monte Carlo simulation study and an electronic-mail emotion/adoption study", Information systems research, Vol. 14 No. 2, 189-217.

Cialdini, R. B., Borden, R. J., Thorne, A., Walker, M. R., Freeman, S., \& Sloan, L. R. (1976), "Basking in reflected glory: Three (football) field studies", Journal of personality and social psychology, Vol. 34 No. 3, 366.

Cialdini, R. B., \& Richardson, K. D. (1980), "Two indirect tactics of image management: Basking and blasting", Journal of Personality and Social Psychology, Vol. 39 No. 3, 406.

Comisky, P., Bryant, J., \& Zillmann, D. (1977), “Commentary as a substitute for action”, Journal of Communication, Vol. 27 No. 3, 150-153. 
What is eSports and why do people watch it?

Courtois, C., Mechant, P., De Marez, L., \& Verleye, G. (2009), "Gratifications and seeding behavior of online adolescents", Journal of Computer-Mediated Communication, Vol. 15 No. $1,109-137$.

Davis, F. D. Bagozzi, R. P. and Warshaw, P. R. (1989), "User acceptance of computer technology: a comparison of two theoretical models", Management Science, Vol. 35 No. 8, 982-1003.

Davis, R., Lang B., \& Gautam, N. (2013), "Modeling utilitarian-hedonic dual mediation (UHDM) in the purchase and use of games", Internet Research, Vol. 23 No. 2, 229-256.

Dietz-Uhler, B., Harrick, E. A., End, C., \& Jacquemotte, L. (2000), "Sex differences in sport fan behavior and reasons for being a sport fan”, Journal of Sport Behavior, Vol. 23 No. 3, 219.

Duncan, M. C., \& Brummett, B. (1989), "Types and sources of spectating pleasure in televised sports”, Sociology of Sport Journal, Vol. 6 No. 3, 195-211.

Eastman, S. T., \& Land, A. M. (1997), "The best of both worlds: Sports fans find good seats at the bar”, Journal of Sport \& Social Issues, Vol. 21 No. 2, 156-178.

Ebersole, S. (2000), "Uses and gratifications of the web among students", Journal of ComputerMediated Communication, Vol. 6 No. 1.

Farquhar, L. K., \& Meeds, R. (2007), “Types of fantasy sports users and their motivations", Journal of Computer-Mediated Communication, Vol. 12 No. 4, 1208-1228.

Fink, J. S., Trail, G. T., \& Anderson, D. F. (2002), "Environmental factors associated with spectator attendance and sport consumption behavior: gender and team differences", Sport Marketing Quarterly, Vol. 11 No. 1, 8-19.

Funk, D. C., \& James, J. D. (2006), "Consumer loyalty: The meaning of attachment in the development of sport team allegiance”, Journal of Sport Management, Vol. 20 No. 2, 189.

Gantz, W. (1981), “An exploration of viewing motives and behaviors associated with television sports”, Journal of Broadcasting \& Electronic Media, Vol. 25 No. 3, 263-275.

Gantz, W., \& Wenner, L. A. (1991), "Men, women, and sports: Audience experiences and effects", Journal of Broadcasting \& Electronic Media, Vol. 35 No. 2, 233-243.

Gantz, W., \& Wenner, L. A. (1995), "Fanship and the television sports viewing experience", Sociology of Sport Journal, Vol. 12, 56-56.

Guttmann, A. (1996), The erotic in sports, Columbia University Press.

Hamari, J. (2013), “Transforming Homo Economicus into Homo Ludens: A field experiment on gamification in a utilitarian peer-to-peer trading service", Electronic Commerce Research and Applications, Vol. 12 No. 4, 236-245.

Hamari, J., Huotari, K., \& Tolvanen, J. (2015), "Gamification and economics”, in S. P. Walz \& S. Deterding (Eds.), The Gameful World: Approaches, Issues, Applications, MIT Press, Cambridge, MA, pp. 139-161.

Hamari, J., Keronen, L., \& Alha, K. (2015b), "Why do people play games? A review of studies on adoption and use", in proceedings of the 48th Annual Hawaii International Conference on System Sciences (HICSS), Hawaii, USA, January 5-8, 2015. 
What is eSports and why do people watch it?

Hamari, J. and Koivisto, J. (2015), “Why do people use gamification services?”, International Journal of Information Management, Vol. 35 No. 4, 419-431.

Hamari, J. and Lehdonvirta, V. (2010), "Game Design as Marketing: How Game Mechanics Create Demand for Virtual Goods", International Journal of Business Science \& Applied Management, Vol. 5 No. 1, 14-29.

Hamari, J., \& Tuunanen, J. (2014), "Player types: A meta-analysis", Transactions of the Digital Games Research Association, Vol. 1 No. 2, 29-53.

Hamilton, W. A., Garretson, O., \& Kerne, A. (2014), "Streaming on twitch: fostering participatory communities of play within live mixed media", in Proceedings of the SIGCHI Conference on Human Factors in Computing Systems, ACM, pp. 1315-1324.

Hanson, G., \& Haridakis, P. (2008), "YouTube users watching and sharing the news: A uses and gratifications approach", Journal of Electronic Publishing, Vol. 11 No. 3.

Heeks, R. (2009), "Understanding 'gold farming' and real-money trading as the intersection of real and virtual economies", Journal For Virtual Worlds Research, Vol. 2 No. 4.

Huang, L.-Y. and Hsieh, Y.-J. (2011), "Predicting online game loyalty based on need gratification and experiential motives", Internet Research, Vol. 21 No. 5, 581-598.

Hutchins, B. 2008, "Signs of meta-change in second modernity: the growth of e-sport and the world cyber games", New Media and Society, Vol. 10 No. 6, 851-869.

James, J. D., \& Ridinger, L. L. (2002), "Female and male sport fans: A comparison of sport consumption motives", Journal of Sport Behavior, Vol. 25 No. 3, 260.

Jansz, J., Avis, C. and Vosmeer, M. (2010), "Playing The Sims2: An exploration of gender differences in players' motivations and patterns of play", New Media \& Society, Vol. 12 No. $2,235-251$.

Johnson, P. R., \& Yang, S. (2009), "Uses and gratifications of Twitter: An examination of user motives and satisfaction of Twitter use", in Communication Technology Division of the annual convention of the Association for Education in Journalism and Mass Communication, Boston, MA.

Joinson, A. N. (2008), "Looking at, looking up or keeping up with people?: motives and use of facebook", in Proceedings of the SIGCHI conference on Human Factors in Computing Systems, ACM, pp. 1027-1036.

Jonasson, K., \& Thiborg, J. (2010), "Electronic sport and its impact on future sport", Sport in Society, Vol. 13 No. 2, 287-299.

Jung, J. H., Schneider, C., \& Valacich, J. (2010), "Enhancing the motivational affordance of information systems: The effects of real-time performance feedback and goal setting in group collaboration environments", Management Science, Vol. 56 No. 4, 724-742.

Kallio, K. P., Mäyrä, F., \& Kaipainen, K. (2011), “At least nine ways to play: Approaching gamer mentalities", Games and Culture, Vol. 6 No. 4, 327-353.

Karp, D. A., \& Yoels, W. C. (1990), "Sport and urban life”, Journal of Sport \& Social Issues, Vol. 14 No. 2, 77-102. 
What is eSports and why do people watch it?

Koivisto, J. and Hamari, J. (2014), "Demographic differences in perceived benefits from gamification", Computers in Human Behavior, Vol. 35, 179-188.

Kozinets, R. V., Sherry, J. F., Storm, D., Duhachek, A., Nuttavuthisit, K., \& DeBerry-Spence, B. (2004), "Ludic agency and retail spectacle", Journal of Consumer Research, Vol. 31 No. 3, 658-672.

Karhulahti, V. M. (2016), "Prank, Troll, Gross and Gore: Performance Issues in Esport LiveStreaming", in Proceedings of DiGRA FDG Conference, Dundee, Scotland, 1-6 August, 2016.

Katz, E., Blumler, J. G., \& Gurevitch, M. (1973), "Uses and gratifications research", Public opinion quarterly, 509-523.

Katz, E., Haas, H., \& Gurevitch, M. (1973), "On the use of the mass media for important things", American sociological review, 164-181.

Krohn, F. B., Clarke, M., Preston, E., McDonald, M., \& Preston, B. (1998), "Psychological and sociological influences on attendance at small college sporting events", College Student Journal, Vol. 32, 277-288.

LaRose, R., \& Eastin, M. S. (2004), “A social cognitive theory of Internet uses and gratifications: Toward a new model of media attendance", Journal of Broadcasting \& Electronic Media, Vol. 48 No. 3, 358-377.

Lehdonvirta, V. (2005), "Real-Money Trade of Virtual Assets: New Strategies for Virtual World Operators", in Proceedings of the 2005 Conference on Future Play (Future Play 2005), Lansing, MI, USA, October 13-15.

Lehdonvirta, V. (2010), "Virtual worlds don't exist: Questioning the dichotomous approach in MMO studies", Game Studies, Vol. 10 No. 1.

Lehdonvirta, V., \& Castronova, E. (2014), Virtual economies: Design and analysis, MIT Press.

Lever, J. (1983), Soccer madness, University of Chicago Press, Chicago.

Lin, C. A. (2002), "Perceived gratifications of online media service use among potential users", Telematics and Informatics, Vol. 19 No. 1, 3-19.

Lu, H.-P. and Wang, S.-M. (2008), "The role of Internet addiction in online game loyalty: An exploratory study", Internet Research, Vol. 18 No. 5, 499-519.

Melnick, M. J. (1993), "Searching for sociability in the stands: A theory of sports spectating", Journal of Sport Management, Vol. 7 No. 1, 44-60.

Milne, G. R., \& McDonald, M. A. (1999), Sport marketing: Managing the exchange process, Jones $\&$ Bartlett Learning.

Morschheuser, B., Hamari, J., \& Koivisto, J. (2016), "Gamification in crowdsourcing: A review", in Proceedings of the 49th Annual Hawaii International Conference on System Sciences (HICSS), Hawaii, USA, January 5-8, 2016. DOI: 10.1109/HICSS.2016.543.

Mäyrä, F., Karvinen, J., \& Ermi, L. (2016), “Pelaajabarometri 2015 Lajityyppien suosio”, TRIM Research Reports, Vol. 21. 
What is eSports and why do people watch it?

Nakamura, L. (2009), "Don't hate the player, hate the game: The racialization of labor in World of Warcraft”, Critical Studies in Media Communication, Vol. 26 No. 2, 128-144.

Nelson, M. J. (2012), "Soviet and American precursors to the gamification of work", in Proceeding of the 16th International Academic MindTrek Conference, ACM, pp. 23-26.

Papacharissi, Z., \& Mendelson, A. (2010), “12 Toward a new(er) sociability: uses, gratifications and social capital on Facebook", Media perspectives for the 21st century, 212.

Papacharissi, Z., \& Rubin, A. M. (2000), "Predictors of Internet use", Journal of Broadcasting \& Electronic Media, Vol. 44 No. 2, 175-196.

Peterson, E. M., \& Raney, A. A. (2008), "Reconceptualizing and reexamining suspense as a predictor of mediated sports enjoyment", Journal of Broadcasting \& Electronic Media, Vol. 52 No. 4, 544-562.

Raney, A. A., Depalma, A. J. (2006), "The effect of viewing varying levels and contexts of violent sports programming on enjoyment, mood, and perceived violence", Mass Communication \& Society, Vol. 9 No. 3, 321-338.

Robinson, M. J., \& Trail, G. T. (2005), "Relationships among spectator gender, motives, points of attachment, and sport preference", Journal of Sport management, Vol. 19 No. 1, 58-80.

Robinson, M. J., Trail, G. T., \& Kwon, H. (2004), "Motives and points of attachment of professional golf spectators," Sport Management Review, Vol. 7 No. 2, 167-192.

Sargent, S. L., Zillmann, D., \& Weaver, J. B. (1998), "The gender gap in the enjoyment of televised sports", Journal of Sport \& Social Issues, Vol. 22 No. 1, 46-64.

Scholz, T. M. (2012), "New Broadcasting Ways In IPTV - The Case of the Starcraft Broadcasting Scene”, World Media Economics \& Management Conference.

Seo, Y. (2013), "Electronic sports: A new marketing landscape of the experience economy", Journal of Marketing Management, Vol. 29 No. 13-14, 1542-1560.

Seo, Y. (2015), "Professionalized consumption and identity transformations in the field of eSports", Journal of Business Research.

Seo, Y., \& Jung, S. U. (2014), "Beyond solitary play in computer games: The social practices of eSports”, Journal of Consumer Culture, 1-21.

Seo, W. J., \& Green, B. C. (2008), "Development of the motivation scale for sport online consumption”, Journal of Sport Management, Vol. 22 No. 1, 82.

Sherry, J. L., Lucas, K., Greenberg, B. S., \& Lachlan, K. (2006), Video game uses and gratifications as predictors of use and game preference. Playing video games: Motives, responses, and consequences, 213-224.

Sjöblom, M. \& Hamari, J. (2016), "Why Do People Watch Others Play Video Games? An Empirical Study on the Motivations of Twitch Users", SSRN.

Smith, G. J. (1988), “The noble sports fan”, Journal of Sport \& Social Issues, Vol. 12 No. 1, 54-65. 
What is eSports and why do people watch it?

Su-lin, G., Tuggle, C. A., Mitrook, M. A., Coussement, S. H., \& Zillmann, D. (1997), "The thrill of a close game who enjoys it and who doesn't?", Journal of Sport \& Social Issues, Vol. 21 No. $1,53-64$.

Taylor, T. L. (2002), Living digitally: Embodiment in virtual worlds. In The social life of avatars, Springer, London, pp. 40-62.

Taylor, T.L. (2012), “T.L. Taylor on Live Streaming”, Computer Games and the Future of Spectatorship, Berkman Luncheon Series, Berkman Centre, June 5.

Taylor, T.L. (2012), Raising the Stakes: E-sports and the professionalization of computer gaming. MIT Press, MA.

Taylor, T. L., and Witkowski, E. (2010), "This is how we play it: what a mega-LAN can teach us about games", in Proceedings of the 5th International Conference on the Foundations of Digital Games, ACM, New York, NY, USA, 195-202.

Tiedemann, C. (2004), "Sport (and culture of physical motion) for historians, an approach to precise the central term(s)", IX international CESH-congress, Crotone, Italy.

Trail, G. T., Anderson, D. F., \& Fink, J. S. (2000), “A theoretical model of sport spectator consumption behavior”, International Journal of Sport Management, Vol. 1 No. 3, 154-180.

Trail, G. T., \& James, J. D. (2001), “The Motivation Scale for Sport Consumption: A Comparison of Psychometric Properties with other Sport Motivation Scales", Journal of Sport Behavior, Vol. 24 No. 1, 108-127.

Trail, G. T. (2012), "Manual for the MSSC", available at http://sportconsumerresearchconsultants.yolasite.com/resources/MSSC\%20Manual\%20\%202012.pdf (retrieved 2 February 2015).

Trepte, S., Reinecke, L., \& Juechems, K. (2012), "The social side of gaming: How playing online computer games creates online and offline social support", Computers in Human Behavior, Vol. 28, 832-839.

Van der Heijden, H. (2004), "User acceptance of hedonic information systems", MIS Quarterly, Vol. 28 No. 4, 695-704.

Wagner, M. (2006), "On the scientific relevance of eSport", in Proceedings of the 2006 International Conference on Internet Computing and Conference on Computer Game Development, CSREA Press, Las Vegas, Nevada, 437-440.

Wang, Q., Fink, E. L., \& Cai, D. A. (2008), "Loneliness, gender, and parasocial interaction: A uses and gratifications approach", Communication Quarterly, Vol. 56 No. 1, 87-109.

Wann, D. L. (1995), "Preliminary validation of the sport fan motivation scale", Journal of Sport \& Social Issues, Vol. 19 No. 4, 377-396.

Wann, D. L. (1997), Sport psychology, Pearson College Division.

Wann, D. L., Allen, B., \& Rochelle, A. R. (2004), "Using sport fandom as an escape: Searching for relief from under-stimulation and over-stimulation", International Sports Journal, Vol. 8 No. 1,104 . 
What is eSports and why do people watch it?

Wann, D. L., Grieve, F. G., Zapalac, R. K., \& Pease, D. G. (2008), "Motivational profiles of sport fans of different sports", Sport Marketing Quarterly, Vol. 17 No. 1, 6.

Wann, D. L., Schrader, M. P., \& Wilson, A. M. (1999), "Sport fan motivation: Questionnarie validation, comparisons by sport, and relationship to athletic motivation", Journal of Sport Behavior, Vol. 22 No. 1, 114.

Wann, D. L., \& Wilson, A. M. (1999), "Relationship between aesthetic motivation and preferences for aggressive and nonaggressive sports", Perceptual and motor skills, Vol. 89 No. 3, 931934.

Warr, P. (9 April 2014), "eSports in numbers: Five mind-blowing stats", Red Bull, available at; http://www.redbull.com/en/esports/stories/1331644628389/esports-in-numbers-five-mindblowing-stats (accessed 9 November 2015).

Wei, P.-S. and Lu, H.-P. (2014) Why do people play mobile social games? An examination of network externalities and of uses and gratifications. Internet Research, 24(3), 313-331.

Weiss, T., \& Schiele, S. (2013), "Virtual worlds in competitive contexts: Analyzing eSports consumer needs”, Electronic Markets, Vol. 23 No. 4, 307-316.

Wenner, L. A., \& Gantz, W. (1998), "Watching sports on television: Audience experience, gender, fanship, and marriage", MediaSport, 233-251.

West, R. L., \& Turner, L. H. (2010), Introducing Communication Theory: Analysis and Application. McGrawHill, Boston, MA.

Whiting, A., \& Williams, D. (2013), "Why people use social media: a uses and gratifications approach", Qualitative Market Research: An International Journal, Vol. 16 No. 4, 362-369.

Williams, D., Yee, N. and Caplan, S. E. (2008) Who Plays, How Much, and Why? Debunking the Stereotypical Gamer Profile. Journal of Computer-Mediated Communication, 13(4), 9931018.

Witkowski, E. 2009, "Probing the Sportiness of eSports", in Christophers, J. and Scholz, T. (eds.) eSports Yearbook 2009, Books on Demand GmbH, Norderstedt, Germany, 53-56.

Witkowski, E. 2012, “On the Digital playing Field: How we "Do Sport" With Networked Computer Games", Games and Culture, Vol. 7 No. 5, 349-374.

Woerman, N., \& Kirschener, H. (2015), "Online Livestreams, Community Practices, and Assemblages. Towards a Site Ontology of Consumer Community", Advances in Consumer Research, 43.

Won, J. U., \& Kitamura, K. (2007), "Comparative analysis of sport consumer motivations between South Korea and Japan”, Sport Marketing Quarterly, Vol. 16 No. 2, 93.

Wu, J. H., Wang, S. C., \& Tsai, H. H. (2010), "Falling in love with online games: The uses and gratifications perspective", Computers in Human Behavior, Vol. 26 No. 6, 1862-1871.

Yee, N. (2006a), "Motivations for play in online games", Cyberpsychology and Behavior, Vol. 9 No. 6, 772-775. 
What is eSports and why do people watch it?

Yee, N. (2006b), "The demographics, motivations and derived experiences of users of massivelymultiuser online graphical environments", PRESENCE: Teleoperators and Virtual Environments, 15, 309-329.

Zillmann, D. (1995), "Sports and the media", in J. Mester (Ed.), Images of sport in the world, German Sports University, Cologne, pp. 423-444.

\footnotetext{
i We realize that terms 'virtual world' and 'real world' are not very accurate terms, however, in the lack of better wording and the fact that the terms are rather comprehensible by a variety of scholars with different backgrounds we adopted to use them. For a more elaborate discussion on the paradox of what is real and virtual please see Lehdonvirta (2010) and Taylor (2002).
} 